\title{
FUNDAMENTAL SIGNIFICANCE OF PHYSICAL ACTIVITY FOR SENIORS' HEALTH
}

\author{
Katarzyna Sygit \\ Faculty of Physical Education and Health Promotion, Department of Health Promotion, University of Szczecin, Poland \\ Address for corpespondence: \\ Katarzyna Sygit, $\mathrm{PhD}$ \\ University of Szczecin \\ Department of Health Promotion \\ Faculty of Physical Education and Health Promotion \\ Al. Piastów 40 b, bulding 6, 71-065 Szczecin, Poland \\ E-mail: ksygit@poczta.onet.pl
}

\begin{abstract}
Ahstract. Physical activity is a basic component of geriatric prevention. Lower physical activity of seniors is a cause and effect of many chronic conditions, e.g. type 2 diabetes, obesity, diseases of musculoskeletal system or cancer.

This paper analyzes Polish and international literature in terms of significance of physical activity for keeping and improving health of seniors. Numerous studies carried out at large research facilities all over the world proved that taking up physical activity by seniors is one of the key factors for ensuring better health. It is, however, important to precede workout with medical examination. After that, suitable exercises, their frequency, duration and intensity need to be determined.

The conclusion of this paper is as follows: regular physical activity improves effectiveness of preventive measures and treatments related to diseases such as cardiovascular disease; it also reduces mortality rate and prolongs the period of physical and mental activity of seniors.
\end{abstract}

Key worll:: physical activities, seniors, lifestyle, healthy behaviors

\section{Introduction}

At every stage of human life, the need for physical activity helps maintain one's health (Kaczmarczyk and Trafiałek 2007; Kostka and Bogus 2007). Improving one's fitness level gained at the adolescence and maintaining it throughout the middle age results in better fitness in old age. Physical activity is a basic component of geriatric prevention. Beneficial results of workout depend on the regularity of exercise. Lower physical activity in seniors is both a cause and effect of many chronic conditions, e.g. type 2 diabetes, obesity, diseases of musculoskeletal system or cancer (Knoops et al. 2004; Sumic et al. 2007).

Usually, the process of aging (with its prevailing stereotypes) discourages seniors from physical and social activity. This is further enhanced by ceased professional activity, limitation of social contacts, sense of loneliness and lower motivation for being active. An important element of the workout program is educating and convincing 
seniors to be physically active, encouraging them to continue being active and praising even the slightest successes on their path to better fitness (Corner et al. 2004; Fiatarone et al. 1994; Polak et al. 2007).

\section{Assessing health of seniors before workout}

Numerous studies proved effectiveness of workout (regular physical exercise) in terms of preventing disadvantageous results of the aging process and sedentary lifestyle (Kostka et al. 2001; Pitsavos et al. 2008). Seniors aged $65+$ often suffer from chronic illnesses and disabilities. Usually they require medical attention and social help. These unfavorable phenomena may be prevented, but general practitioners are unwilling to encourage seniors to take up everyday physical workout. The role of the doctor must include: effective persuasion of patients to be physically active, detailed examination, and finally designing an individual and safe workout routine. During a standard appointment, doctors should examine the patients thoroughly in order to determine whether they are healthy enough to engage in physical workout. 'Being healthy' means lack of illnesses which could prevent from participation in workout (Sygit 2008). Physical activity is aimed at reducing risk of certain chronic degenerative diseases and improving metabolism, $\mathrm{Vo}_{2}$ max and better functioning on a daily basis (Kliginan 1999; Kostka et al. 2001).

During medical check-ups, the doctor needs to determine possible counter indications related to cardiac stress tests and subsequent workout, as well as training limitations of their senior patients. Factors to be considered include: patient's previous activity level, current activity (frequency, duration, intensity of training), acute and chronic illnesses (with special consideration given to chronic obstructive pulmonary disease, cardiovascular disease and severe mobility limitations due to joint diseases). To obtain full set of data on a patient, a family history needs to be verified (incl. cardiovascular disease, respiratory disease and determining risk factors for the coronary artery disease). During the verification of the family history, the doctor should consider all systems and organs. Risk factors that could limit cardiac stress tests also need to be determined (Borowiak and Kostka 2004; Fiatarone et al. 1994).

Unfortunately, workout does sometimes result in adverse effects, including deaths, but usually they result from ongoing cardiovascular disease. Rules for qualifying and counter indications for cardiac stress tests and trainings for seniors are the same as for younger patients (Chipperfieid 2008; Psaltopoulou et al. 2008).

\section{Assessing functions of the cireulatory system}

Strict counter indications for cardiac stress tests are: new changes in the ECG, acute myocardial infarction, unstable myocardial ischemia, atrioventricular block and acute congestive cardiac failure. Conditional counter indications are: high blood pressure, cardiomyopathy, valvular heart disease, complex ventricular extra beats and metabolic decompensation (Sygit 2008).

The American College of Sports Medicine (ACSM) recommends cardiac stress tests on a treadmill before proceeding to intense workout (over $60 \%$ of the maximal oxygen uptake) for men over 40 and women over 50 years old. The test should also be performed with seniors with cardiovascular disease risk factors, irrespectively of their ailments and expected intensity of workout. Cardiac stress test is also necessary when the patient is 65+ and leads a sedentary life. Cardiac stress test on a treadmill is also helpful to plan workout intensity. If treadmill is not available, normal pulse recovery test (Kasch's test), presented in Table 1, must suffice to assess patient's functions (Kliginan 1999). 
Table 1. Kasch's Pulse Recovery Test

\begin{tabular}{lcc}
\hline \multicolumn{1}{c}{ Function } & $\begin{array}{c}\text { Heartbeat (beats per minute) } \\
\text { in patients aged } 50-60\end{array}$ & $\begin{array}{c}\text { Heartbeat (beats per minute) } \\
\text { in patients aged 66 }\end{array}$ \\
\hline Men & $72-82$ & $72-86$ \\
- Excellent & $89-97$ & $89-95$ \\
- Good & $98-101$ & $97-102$ \\
- Above average & $105-111$ & $104-113$ \\
- Average & $113-118$ & $114-119$ \\
- Below average & $122-128$ & $122-128$ \\
- Poor & $131-150$ & $133-152$ \\
- Very poor & & \\
Women & $74-92$ & $73-86$ \\
- Excellent & $97-103$ & $93-100$ \\
- Good & $106-111$ & $104-114$ \\
- Above average & $113-117$ & $117-121$ \\
- Average & $119-127$ & $123-127$ \\
- Below average & $129-136$ & $129-134$ \\
- Poor & $142-151$ & $135-151$ \\
- Very poor & &
\end{tabular}

The test assumes that the better oxygen function of a patient the quicker they regain the initial heartbeat after workout. Before commencing the test, pulse and blood pressure need to be measured. Next, patients spend 3 minutes walking up and down (using both legs) on a 30-cm step at the rate of 24 up-and-downs per minute. To facilitate the correct rate, a metronome may be set at 96 beats per minute. Pulse and blood pressure must be measured 1 minute after completion of the test. Functions of respiratory system may be measured with forced vital capacity of lungs and forced expiratory volume in 1 second.

Measurement of musculoskeletal system functions should include muscle strength (hand grip strength) and joint movement ranges. Grip strength (measured with a dynamometer) helps predict functional limitations. Simple measurement of strength and endurance of muscles consists of holding tight the dynamometers as long as possible. Thus, data for comparative assessment of subsequent trainings is obtained. The other strength and function indicator is Squat-Stand Up Test, which is very easy to conduct (Kliginan 1999; Sygit 2008).

\section{Designing a training plan}

Designing a workout plan is similar to prescribing medicine, planning a surgery or determining treatments. It is a compromise between expected benefits and possible side effects. After thorough consideration given to all factors, doctors and patients should work together to develop an optimal workout plan. The most important aspects are: determining the aim of exercises (e.g. osteoporosis prevention, reducing body mass, preparing for a marathon) and patient's preferences. One should consider expanding current forms of activity because selecting workout which is pleasurable for a patient guarantees persistence (Borowiak and Kostka 2004; Fiatarone et al. 1994).

The American College of Sports Medicine presented its exercise recommendations for healthy seniors and other adults. Thus, a basic exercise plan was created; it should be presented to a patient, with consideration given to their health level and aims of particular exercises (Kostka et al. 2001; Lampinen et al. 2006).

During initial tests, similarly to planning the trainings, one should consider 5 basic physical ability aspects: circulatory system functions, strength and endurance of muscles, agility, body composition and sense of balance. 
Many seniors have low proportion of lean body mass and weakened muscle strength. Benefits of strength training for these patients are often ignored, therefore the American College of Sports Medicine highlights the importance of this type of training in its newest recommendations. Considering all of the above-mentioned factors, both doctors and patients should determine the ideal physical activity level. The minimal aim should be to maintain current fitness level, and the optimal - to improve it. The type and intensity of exercise may change along with changes in patient's functions (Kostka 2009; Sumukadas et al. 2007).

\section{Selecting exercise types}

Workout plan should include type, frequency, duration and intensity of exercises aimed at improving all aspects of physical fitness. Type of exercise often depends of availability of facilities and sports equipment, but patients' preferences and expectations should not be ignored, e.g. golf lovers should be encouraged to do certain exercises on the treadmill and strength trainings. The doctor should balance health benefits of particular types of exercise and physical limitation of the patient. For example, marching, cycling and swimming have the same beneficial effects on the circulatory system functions. Improved calcification of bones is obtained, however, by marching because this type of activity ensures full strain on the whole musculoskeletal system, while swimming works best for patients with limited joint mobility.

Alternative workout is the best compromise between numerous forms of training. Patients can engage in various forms of physical activity in a week. Alternative training effectively combats boredom, engages more muscle groups and reduces strain injuries of the musculoskeletal system (Blair et al. 1995; Chipperfieid 2008; Onder et al. 2002).

\section{Determining frequency, duration and intensity of workout}

In order to motivate a senior to be persistent in their trainings, the workout plan may be diversified. It must be remembered that results depend on the intensity of exercise. Although more frequent, longer and more difficult exercises require better preparation, the relation between results and effort are almost linear. Sense of satiety is a natural and desirable mechanism which prevents the patient from over-training and injuries. It is hard to believe how little physical activity is enough to conform to recommendations of the Center for Disease Control and Prevention and the National Institutes of Health. Doctors and physiotherapists often design workout plans with two options: minimal and optimal. Patients are supposed to exercise according to the former option when they are very busy, and fulfill the latter whenever they have more time for exercise (Aria et al. 2007).

Recommendations for exercise intensity are usually given in ranges (e.g. target heartbeat: 120-145 per minute, muscle fatigue after 8-12 repetitions in a series). Expected norms of heartbeat in all age groups, found in literature, have little usability in the population of seniors, and often are erroneous (the recommended $70-85 \%$ of max. heart beat often means difference of 15-20 heartbeats per minute in practice). Physiological response occurs when stimuli are stronger than the current activity level. Many people do not appreciate physical activity, seeing it as uncomfortable, risky and unjustified. M.E. Tinetti roved, however, that strength training is effective and safe even for 90 -year-olds. Their study recommended changing frequency and intensity of workout once the improved functions were obtained. When designing a workout plan, it is essential to monitor or teach patients how to monitor their progress (Tinetti 1986). 
Determining workout aims requires knowledge about progress equivalents for metabolic exercise. A table was published which presents different types of physical activity and their metabolic equivalents. We encourage doctors to familiarize themselves with this list and use it during designing workout plan for their patients, according to their health and geographical conditions.

In order to determine the intensity of aerobic exercise, Borg Rating of Perceived Exertion is often used (Table 2) (Tinetti 1986; Sygit 2008).

Tahle 2. Borg Rating of Perceived Exertion

\begin{tabular}{ll}
\hline \multicolumn{1}{c}{ Value } & \multicolumn{1}{c}{ Exertion } \\
\hline $6-7$ & Extremely light \\
$8-9$ & Very light \\
$10-11$ & Light \\
$12-13$ & Somewhat hard \\
$14-15$ & Hard \\
$16-17$ & Very hard \\
$18-20$ & Extremely hard \\
\hline
\end{tabular}

This scale may also be used in relation to strength and stretching exercises. Physiotherapists often recommend exercise that are 'somewhat hard' or 'hard' to perform (13-15 points on the Borg scale) to healthy and young individuals, while 'light' and 'somewhat hard' (11-13 points) to seniors. Once functions have improved, patient should increase intensity or duration of workout. During strength training one must remember to exercise until muscles are fatigued, which occurs after 8-12 repetitions. For seniors, it is better to perform more repetitions (12-15) with lower weights. Weight should be increased when patient is able to easily repeat the exercise 13 times; then, the whole process is repeated (Tinetti 1986).

\section{Conclusions}

Aging of Europe and Poland's population is probably the biggest medical and socio-political challenge of the coming years. It is predicted that by 2050 seniors aged 60-79 will constitute a quarter of the EU population. Maintaining satisfactory health and functions of seniors, including prolonged professional life and reducing medical costs, are priorities for the European Commission (Gębska-Kuczerowska 2002; Kostka et al. 2009).

Regular physical activity, counteracting the effects of hypokinesis, has a number of beneficial effects for seniors. It is a universal medicine used in prevention and treatment of age-related illnesses (coronary artery disease, hypertension, obesity, hypercholesterolemia, diabetes, and osteoporosis). It results in increased sensitivity to insulin, improved glucose tolerance and lower risk of diabetes. Regular physical activity in seniors results in lower incidence of infections and normalizes lipid values (Gębska-Kuczerowska 2002; Polak 2007).

Workout plays a significant role in more optimistic perception of life quality. Number of studies proved that regular workout by seniors resulted in higher assessment of life quality, better mobility in everyday life, being able to take care of oneself, doing household chores, lower risk of depression and less frequent pain and anxiety incidence in seniors over 65 . Beneficial impact of workout is especially notable in seniors with disabilities and mobility limitations. Regular workout reduces mortality rate, but also prolongs the period of self-reliance and independence from others in everyday life, as well as improves quality of life of seniors. Physical and mental health and regular 
physical activity impact senior's life quality more than cardiovascular disease or hospitalization (Lampinen 2006; Petrella 1999; Sumic et al. 2007).

To summarize, regular physical activity improves effectiveness of preventive measures and treatments related to cardiovascular disease; it reduces mortality rate and prolongs the period of physical and mental activity of seniors (Korner et al. 2004; Polak et. al. 2007).

\section{References}

Aria A., Ishida K., Tomimori M., Katsumata Y., Grave J., Tamashiro H. Association between lifestyle activity and depressed mood among home-dwelling older people: a community-based study in Japan. Aging\&Mental Health. 2007; 11: 547-555.

Blair S.N., Kohl H.W.I., Barlow C.E.. Paffenbarger R.S. Jr., Gibbons L.W., Macera C.A. Changes in physical fitness and all-cause mortality: a prospective study of healthy and unhealthy men. JAMA. 1995; 273: 1093-1098.

Borowiak E., Kostka T. Predictors of quality of life in older people living at home and in institutions. Aging Clin. Exp. Res. 2004; 16: 212-220.

Chipperfieid J.G. Everyday physical activity as a predictor of late-life mortality. The Gerantologist. 2008; 48: 349-357.

Corner L., Brittain K., Bond J. Social aspects of ageing. Psychiatry 2004; 3: 5-7.

Di Bari M., van de Poll-Franse L.V., Onder G., Kritchevsky S.B., Newman A., Harris T.B., Williamson J.D., Marchionni N., Pahor M. Antihypertensive medications and differences in muscle mass in older persons: the Health, Aging and Body Composition Study. J. Am. Geriatr. Soc. 2004; 52: 961-966.

Fiatarone M.A., O'Neill E.F., Doyle N., Clements K.M., Solares G.R., Nelson M.E., Roberts S.B., Kehayias J., Lipsitz L., Evans W.J. Exercise training and nutritional supplementation for physical frailty in very elderly people. N. Engl. J. Med. 1994; 330: 1769-1775.

Gębska-Kuczerowska A. Ocena zależności miedzy aktywnością a stanem zdrowia ludzi w wieku podeszłym. Przegl. Epidemiol. 2002; 56: $471-477$.

Kaczmarczyk M., Trafiałek E. Aktywizacja osób w starszym wieku jako szansa na pomyślne starzenie. Gerontologia Polska. 2007; 15: 116-118.

Kliginan E.W. Recommending exercise to healthy older adults: The Physician and Sports Medicine. 15, 1999.

Knoops K.T.B., de Groot L.G.M., Kromhout D., Perrin A. Mediterranean Diet, Lifestyle Factors, and 10-Year Mortality in Elderly European Men and Women: The HALE Project. JAMA. 2004; 292: 1433-1439.

Kostka T., Bogus K. Independent contribution of overweight/obesity and physical inactivity to lower health-related quality of life in community-dwelling older subjects. Z. Gerontol. Geriatr. 2007; 40: 43-51.

Kostka T., Drygas W., Jegier A., Zaniewicz D. Aerobic and anaerobic power in relation to age and physical activity in men. Int. J. Sports Med. 2009; 30: 225-230.

Kostka T., Lacour J.-R., Bonnefoy M. Response of blood lipids to physical exercise in elderly subjects. Prev. Cardiol. 2001; 4: 122-125, 131.

Lampinen P., Heikkinen R., Kauppinen M., Heikkinen E. Activity as a predictor of mental well-being among older adults. Aging\&Mental Health. 2006; 10: 454-466.

Onder G., Penninx B.W., Balkrishnan R. Relation between use of angiotensin-converting enzyme inhibitors and muscle strength and physical function in older women: an observational study. Lancet. 2002; 359 (9310): 926-930.

Petrella R.J. Exercise for older patients with chronic disease: The Physician and Sports Medicine. 11, 1999.

Pitsavos C, Kavouras S.A., Panagiotakos D.B., Arapi S., Anastasiou C.A., Zombolos S., Stravopodis P., Mantas Y., Kogias Y., Antonoulas A., Stefanadis C. Physical activity status and acute coronary syndromes survival The GREECS (Greek Study of Acute Coronary Syndromes) study. J. Am. Coll. Cardiol. 2008; 51: 2034-2039.

Polak A., Parzych K., Kędziora-Kornatowska K. Poznawczy i praktyczny wymiar gerontologii - interdyscyplinarnej nauki o starzeniu się i starości. Gerontologia Polska. 2007; 15: 51-53

Psaltopoulou T., Kyrozis A., Stathopoulos P., Trichopoulos D., Vassilopoulos D., Trichopoulou A. Diet, physical activity and cognitive impairment among elders: the EPIC-Greece cohort (European Prospective Investigation into Cancer and Nutrition). Public Health Nutr. 2008; 11: 1054-1062. 
Sumic A., Michael U., Carlson N., Howieson D., Kaye J. Physical activity and the risk of dementia in oldest old. J. Aging health. 2007; 19: 242-258.

Sumukadas D., Witham M.D., Struthers A.D., McMurdo M.E. Effect of perindopril on physical function in elderly people with functional impairment: a randomized controlled trial. CMAJ. 2007; 177: 867-874.

Sygit K. Problemy zdrowotne i społeczne seniorów (studium socjomedyczne). Uniwersytet Szczeciński 2008.

Tinetti M.E: Performance-oriented assessment of mobility problems in elderly. J. Am. Geriatr. Soc. 1986.

Cite this article aS: Sygit K. Fundamental Significance of Physical Activity for Seniors' Health. Central European Journal of Sport Sciences and Medicine. 2015; 12 (4): 53-59. 
